\title{
A GENLISEA MYTH IS CONFIRMED
}

Fernando Rivadavia • Rua Inacio Pedroso 230 • 05612-000 • São Paulo, S.P. • Brazil • fe_riva@uol.com.br

Keywords: cultivation: Observations: Genlisea pygmaea, Brazil-physiology: Genlisea pygmaea.

The genus Genlisea comprises approximately 20 known species, divided more or less equally between Africa and the New World tropics and subtropics. The unique inverted "Y"shaped corkscrew traps of Genlisea species as well as the five calyx lobes (versus two or rarely four) allow one to easily differentiate any species in this genus from species belonging to the closely related genus Utricularia, also a member of the Lentibulariaceae family.

All species of Genlisea produce basal rosettes of light to dark-green leaves, which are usually a few millimeters to a few centimeters in length, and which vary from spatulate to filiform in shape. The exceptions include G. angolenensis R.D. Good, G. guianensis N.E. Brown, and $G$. sanariapoana Steyermark which have elongated strap-shaped leaves. Furthermore, the leaves of the latter two species are often deep red in color and may reach $20 \mathrm{~cm}$ in length.

Genlisea aurea A. Saint-Hilaire has one of the most unique leaf rosettes in the genus, consisting of dozens, maybe hundreds, of narrow leaves covered in clear gelatinous mucilage. On the other hand G. uncinata Fromm-Trinta often has only 1-3 leaves per plant and most of the photosynthesis appears to be carried out by the long-lasting inflorescences.

The inflorescences of Genlisea vary widely in size, from hair-thin single-flowered scapes a few millimeters in height in G. filiformis A. Saint-Hilaire to thick succulent scapes over $1.2 \mathrm{~m}$ in length in G. uncinata. Flowers vary in color between yellow, cream, white, lilac, purple, and pink, but do not vary too much in size (Fromm-Trinta 1979; Taylor 1991). The taxonomy of Genlisea is heavily based on inflorescence pubescence: presence or absence of hairs, whether these are glandular or simple, as well as their density and distribution.

The genus Genlisea is divided into two sections, Genlisea and Tayloria, based on the way their fruits open when mature. Section Tayloria represents only three species from Brazil $(G$. uncinata, G. violacea A. Saint-Hilaire, and G. lobata Fromm-Trinta), with fruits that dehisce into two longitudinal valves. Section Genlisea includes all other species in the genus with unique fruits that are circumscissile, splitting in a circumference halfway up from the base as well as along two circles (akin to latitude lines on a globe) further towards the apex (Taylor 1991).

Although only $G$. repens Benj. is reported to form elongated underground stolons-like many Utricularia species-most species of Genlisea do in fact form a very short but visible stem from which arise the basal rosette of photosynthetic leaves, traps, and inflorescences (FrommTrinta 1979; Fischer \& Porembski 2000). When these structures are removed, the stem is usually beige in color and cylindrical to obconical. The largest I have seen were on G. aurea, with stems up to approximately $1.5 \mathrm{~cm}$ in length by $4 \mathrm{~mm}$ in diameter.

Both annual and perennial species are known in the genus Genlisea. Annual species often occur in seasonally moist sandy soils (e.g. G. filiformis) and in thin layers of soil or mosses over rocks on mountainsides (e.g. G. lobata and G. stapfii A. Chev.). Perennial species often occupy permanently boggy areas (e.g. G. hispidula Stapf, G. margaretae Hutchinson, and G. aurea) and sometimes even semi-aquatic habitats on floating mats of dead vegetation at the edges of streams, ponds or lakes (e.g. G. guianensis, G. glandulosissima R.E. Fries, and G. repens) (Fischer \& Porembski 2000; Fromm-Trinta 1979).

A few species of Genlisea (e.g. G. pygmaea A. Saint-Hilaire, G. roraimensis N.E. Brown, and $G$. violacea) do not clearly fit either category, possibly being best described as facultative (optional) annuals. These species are usually found in sandy soils that may be very wet during the rainy season, but which become barely moist to bone-dry during the dry season.

Genlisea pygmaea is a widespread and very polymorphic species. In a previous publication (Rivadavia 2000) I discussed a large form of this taxon - the only one known to me at the time. 


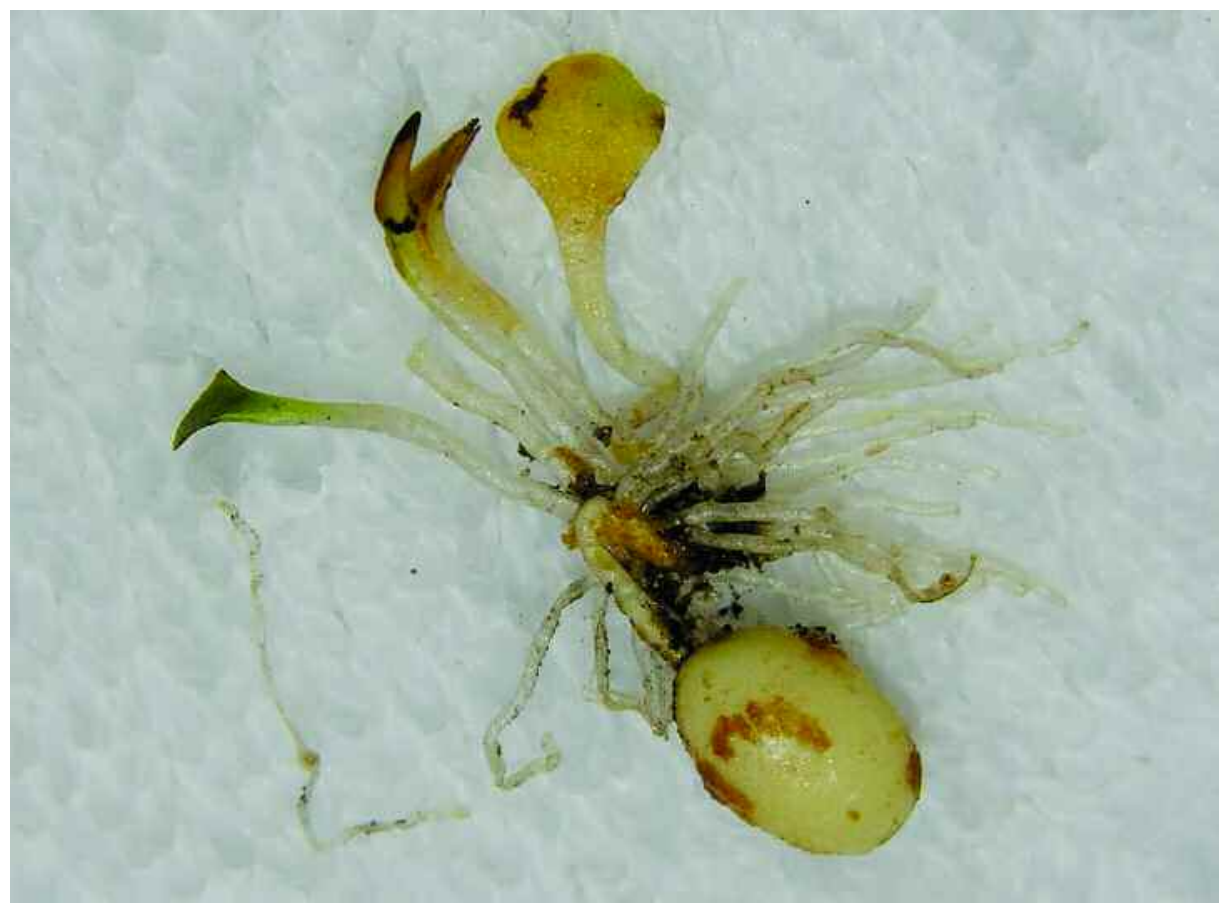

Figure 1: A close view of the tuber attachment in G. pygmaea.

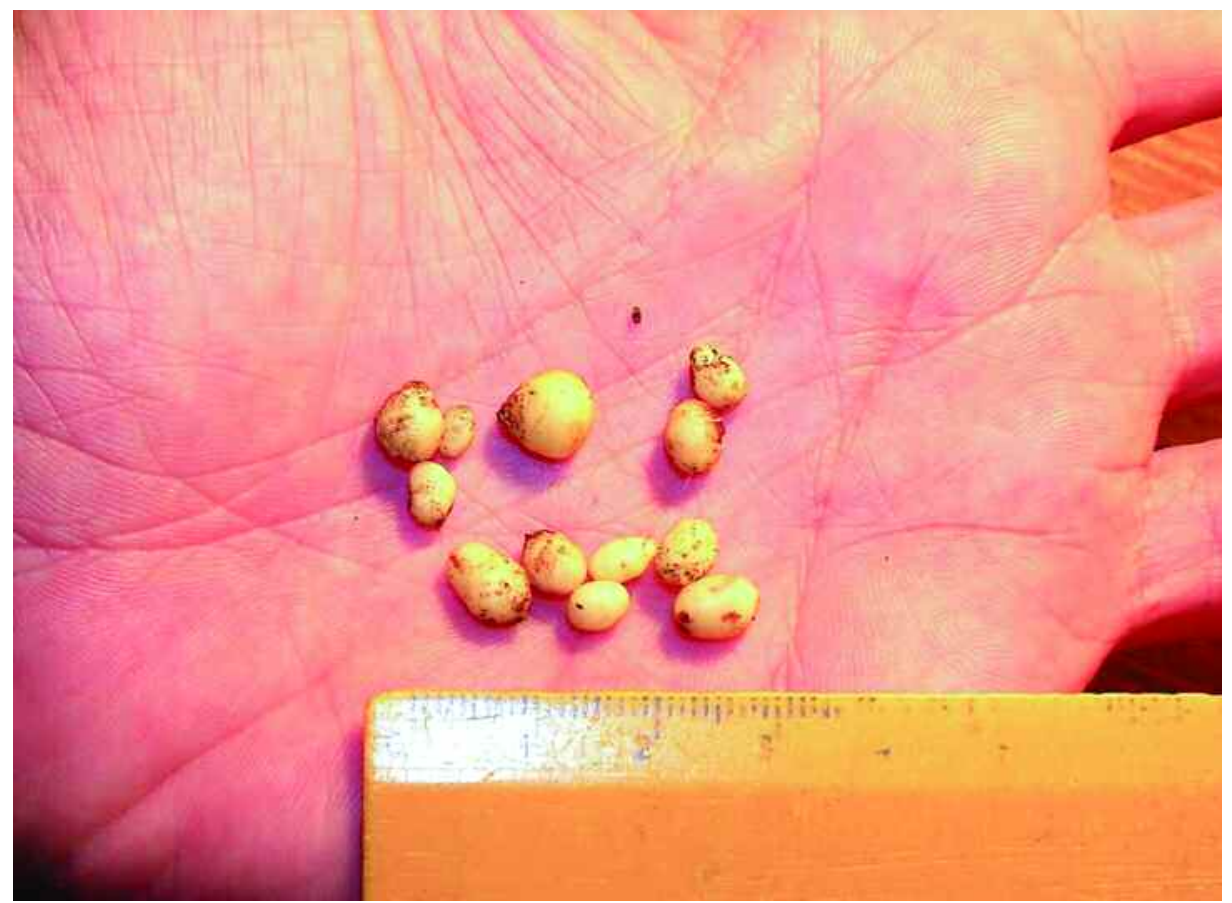

Figure 2: Numerous G. pygmaea tubers in the author's hand. A cm scale bar is shown for reference. 
Since then, I have seen numerous smaller growth types in Brazil (from Minas Gerais state in the southeast to Pará state in the north to Mato Grosso state in the west) and southeastern Venezuela (Gran Sabana, Bolívar state). This species has also been reported for Colombia, Guyana, and Trinidad (Taylor 1991).

Recently, G. pygmaea was reported to produce two kinds of traps; short traps that spread horizontally from the stem and elongated traps that extend vertically into the soil (Studni?ka 1986). Because Genlisea traps are so fragile and often break when collected, dimorphic traps are probably common among other species in the genus and have simply been overlooked. I have personally seen such dimorphism in three other species: G. aurea, G. glandulosissima, and $G$. uncinata.

I have observed G. pygmaea growing in habitats varying from steamy coastal plains near the equator all the way up to cool highlands at $1500 \mathrm{~m}$ altitude. Smaller forms of G. pygmaea grow apparently as annuals in habitats that become heavily desiccated during the dry season. Yet larger forms of this species have always been somewhat of an ecological puzzle to me. Although their habitats also seem to dry out completely, I have found robust $G$. pygmaea specimens in flower very early in the wet season. This suggested to me that they were perennials and that somehow they were able to survive the dry season, maybe by growing in slightly wetter habitats.

I finally solved this puzzle in June 2007, during a trip to the Chapada dos Veadeiros highlands in northeastern Goiás state, in central Brazil. The dry season was picking up momentum and had already taken its toll. Only a few rare patches of the common annuals G. filiformis, Drosera sessilifolia A. Saint-Hilaire, Utricularia laciniata A. Saint-Hilaire \& Gir., and $U$. amethystina Salzm. ex A. Saint-Hilaire \& Gir. were still visible. Winter dormant Drosera species, such as D. montana A. Saint-Hilaire var. montana and D. hirtella A. Saint-Hilaire var. hirtella were already shutting down, while D. cayennensis Sagot ex Diels had already retreated completely underground and left no traces on the soil surface.

At $1470 \mathrm{~m}$ altitude, in a sandy habitat among sparse grasses, where numerous other carnivorous plant species grew sympatrically or in neighboring habitats, I found a population of $G$. pygmaea which also seemed to be shutting down with the oncoming dry season. The leaf rosettes did not look very healthy and only flowerless inflorescences with fruit remained (the characteristic pubescence of the flower scape identified this species). The G. pygmaea common on the Chapada dos Veadeiros is probably the largest form of this species-also found on the Espinhaço Highlands of Minas Gerais in areas surrounding the city of Diamantina and on the Serra do Cipó.

In order to make herbarium specimens of G. pygmaea from this habitat and record its presence there, I began digging up a few plants. As I shook and scraped the sandy soil from around and beneath the rosettes, also removing grasses and other plants, I saw a few small white tubers (see Back Cover). At first I thought they belonged to one of the other plant species. But by the third or fourth scoop of soil, I knew it was too much of a coincidence that those tubers were always located directly beneath the G. pygmaea rosettes!

Although I was already certain of what I had found, I bagged a few scoops of soil with $G$. pygmaea and saved them. Two days later I was c. $250 \mathrm{~km}$ south of the Chapada dos Veadeiros, at a nice hotel in our capital, Brasília. There, I was able to sit calmly in the shower of a well-illuminated bathroom for a few hours, while I slowly and patiently cleaned G. pygmaea rosettes. It was extremely difficult to wash away the soil and remove bits and pieces of other plants without damaging $G$. pygmaea and breaking off the tubers. Out of about five to ten plants that were cleaned, I was only able to keep a tuber attached to the stem of a single specimen, although almost all the leaves and traps broke off.

This specimen allowed me to see how the short stem of G. pygmaea had suddenly made a "U" turn and grown downwards for about half a centimeter, where the tuber was formed (Figure 1). I was able to confirm this a week later while exploring near the town of Cristalina, about $150 \mathrm{~km}$ south of Brasília. There, I found more G. pygmaea, this time growing in open sandy patches, without any other plants growing among them. I collected a few rosettes, and then washed them at night. Once again I was able to obtain a single clean specimen with the tuber still attached. 
Although I saw up to three tubers underneath a few plants, it appears that each leaf rosette produces a single tuber. Multiple tubers probably were a result of multiple plants growing in close proximity. Each tuber measured 2-9mm in length and 2-8 in width (Figure 2). Bits of brown skin were present on the surface of some tubers, coming off very easily.

A few days after discovering the tubers I wrote to my good friend and carnivorous plant enthusiast, Marcos Cardoso, who lives Cuiabá, Mato Grosso state. A few months earlier we had visited together a population of a medium-sized form of G. pygmaea on the nearby Chapada dos Guimarães highlands. After seeing my pictures from the Chapada dos Veadeiros he was easily convinced to revisit this site, which he did a few days later. Although he dug up a several specimens, he saw no signs of tubers on the local G. pygmaea.

Thomas Carow from Germany (one of the greatest carnivorous plant cultivators and explorers) reported seeing tubers in G. pygmaea he collected in Brazil in the late 1980s around Diamantina, Minas Gerais (pers. comm.). I guess nobody really believed him and maybe he did not believe it himself. I know I could not believe my own eyes when I saw them! After all, no species of Genlisea was known to form tubers!

Tubers in G. pygmaea are certainly an adaptation to survive the dry season, which in Brazil south of the Amazon Basin occurs during winter, more or less from May to November. These structures were overlooked for so long because they are probably only produced early in the dry season and are attached to a live leaf rosette for a very short time, maybe 1-3 months. Thus, one would have to collect $G$. pygmaea rosettes at the right time of year in order to find the tubers attached. Several species of Utricularia (e.g., U. brachiata (R.Wight) Oliv., U. campbelliana Oliv., U. geminiloba Benj., U. mannii Oliv., and U. menziesii R.Br.) are also known to form tubers to help survive the dry season (Taylor 1989).

The confirmation that G. pygmaea produces tubers raises several interesting questions. The first of course is whether there are other species in the genus with this ability, but which have also been understudied and thus overlooked. A more specific question would be if all G. pygmaea populations produce tubers or not. And if there are truly annual forms of G. pygmaea that do not produce tubers, should these be separated from the perennials as a different species? And finally, such a case, should the name G. pygmaea be used for the tuberous or non-tuberous plants?

Acknowledgements: I would like to thank Vitor Batista for helping me with the field work carried out with G. pygmaea at the Chapada dos Veadeiros and at Cristalina, as well as Marcos Cardoso for studying G. pygmaea at the Chapada dos Guimarães in search of tubers. I would also like Barry Rice for helpful comments and suggestions. Finally, I want to thank Thomas Carow, for sharing his observations of tubers on G. pygmaea - and for believing what nobody else believed! No permits were required to visit or collect the plants, as described in this article. Voucher specimen of the tuberous Genlisea pygmaea A.Saint-Hilaire: Brasil, Goiás, Município de Alto Paraíso de Goiás, estrada A.Paraíso a Teresina de Goiás, Chapada dos Veadeiros, 23/June/2007, F.Rivadavia \& V.Batista 2611 (SPF).

\section{References}

Fischer, E. and Porembski, S. 2000. Revision of the genus Genlisea (Lentibulariaceae) in Africa and Madagascar with notes on ecology and phytogeography. Nordic J. of Bot. 20(3): 291318.

Fromm-Trinta, E. 1979. Revisão das espécies do gênero Genlisea St.Hil. (Lentibulariaceae) das regiões sudeste e sul do Brasil. Rodriguésia 31/49: 17-139.

Rivadavia, F. 2000. Genlisea pygmaea St. Hil. The Carniv. Pl. Society J. 23: 70-71.

Studnička, M. 1996. Several ecophysiological observations in Genlisea. Carniv. Pl. Newslett. 25: 14-16.

Taylor, P. 1989. The Genus Utricularia —a taxonomic monograph. Kew Bull.Additional Series XIV. HMSO. London.

Taylor, P. 1991. The genus Genlisea. Carniv. Pl. Newslett. 20: 20-26. 


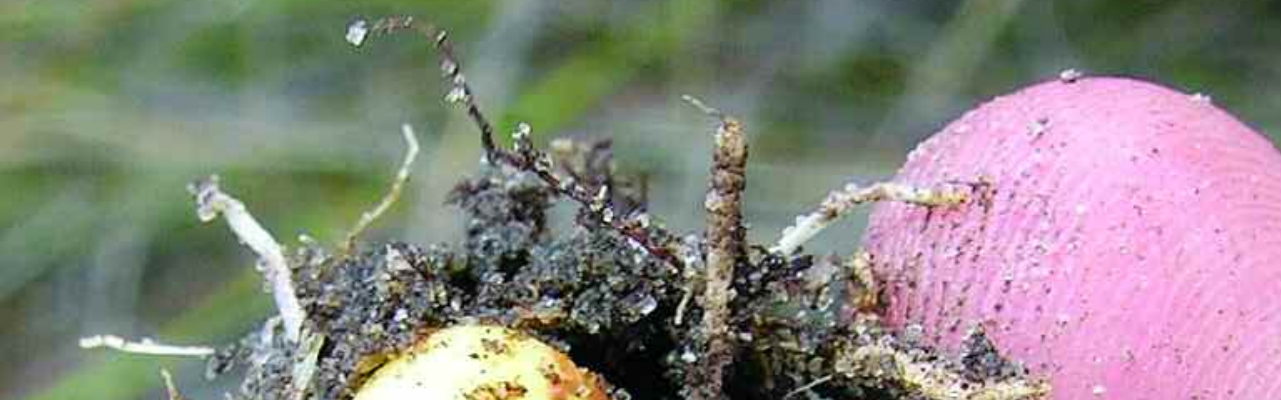

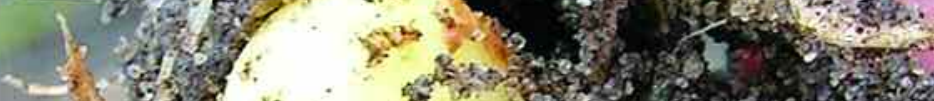

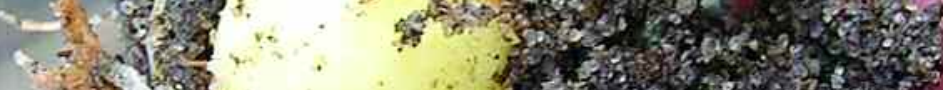

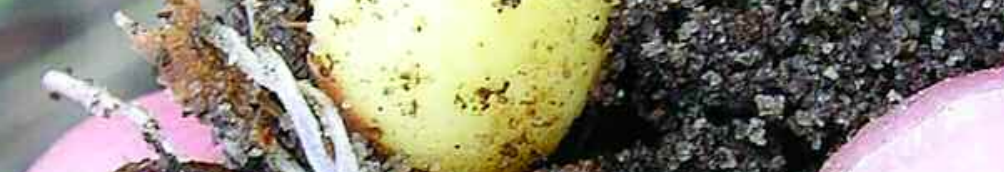

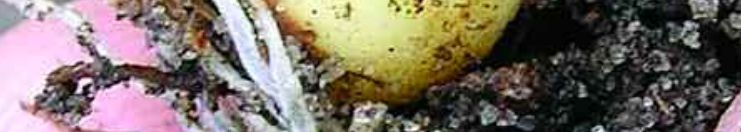

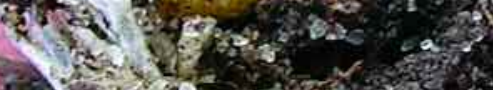

Thes

(3) ins in

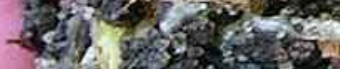

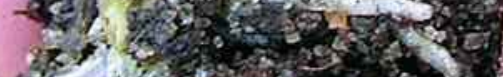
Pind of

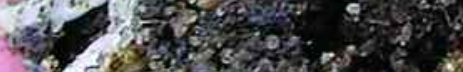

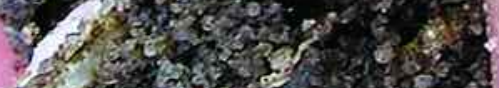
a3.

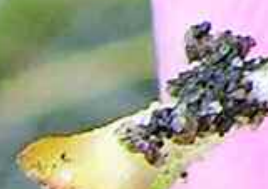
a)
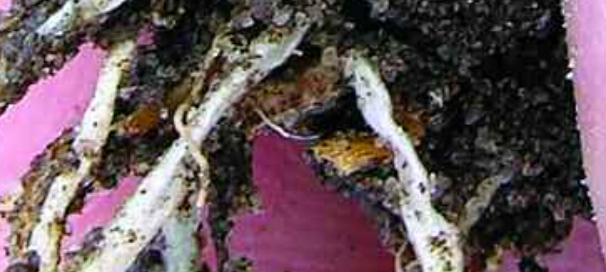
? 11
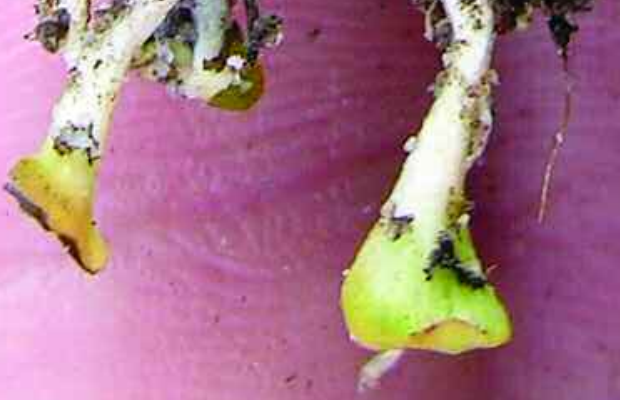


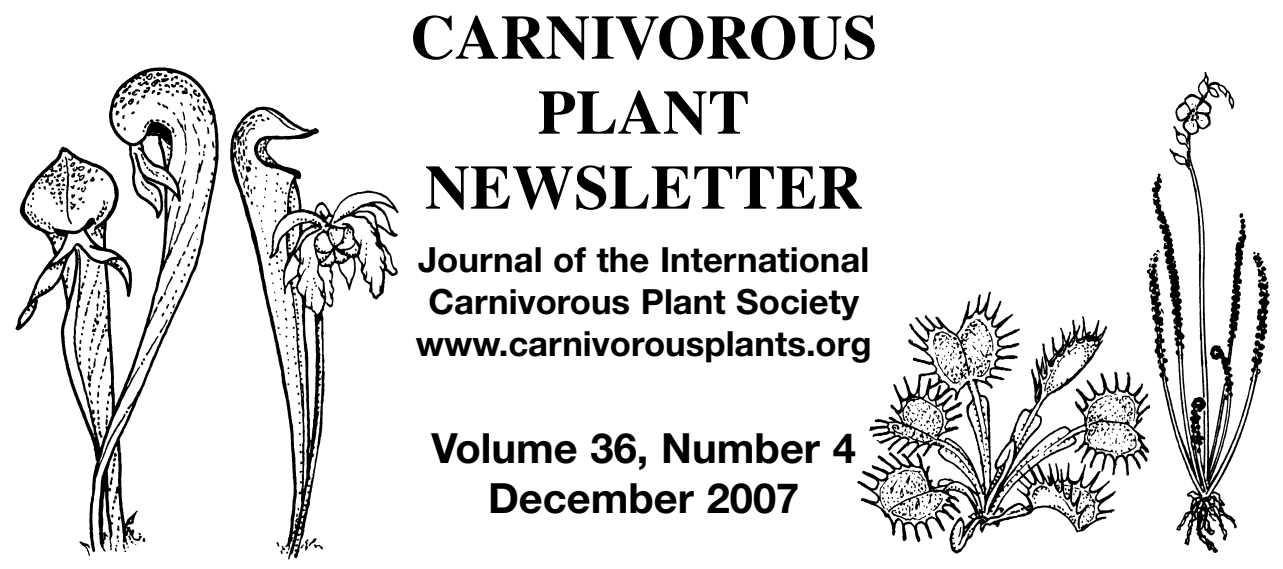

Front Cover: Pinguicula balcanica growing in a streamside site, Pirin Mountain, Bulgaria. Article on page 100. Photograph by Lorenzo Peruzzi.

Back Cover: A remarkable discovery of G. pygmaea with tubers. See article on page 122. Photograph by Fernando Rivadavia.

Carnivorous Plant Newsletter is dedicated to spreading knowledge and news related to carnivorous plants. Reader contributions are essential for this mission to be successful. Do not hesitate to contact the editors with information about your plants, conservation projects, field trips, or noteworthy events. Contributors should review the "Instructions to Authors" printed in the March issue of each year. Advertisers should contact the editors. Views expressed in this publication are those of the authors, not the editorial staff.

All correspondence regarding dues, address changes and missing issues should be sent to the Membership Coordinator at the ICPS. Do not send such correspondence to the editors. Checks for subscriptions and back issues should be made to the ICPS in US funds. Dues for 2007 are $\$ 25$.

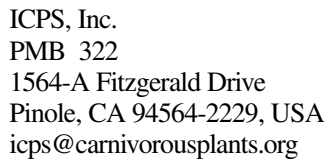

President_ Doug Darnowski, doug@carnivorousplants.org

Vice President Cindy Slezak, email: cindy@carnivorousplants.org

Secretary, Seed Bank John Brittnacher, email: john@carnivorousplants.org, seedbank listed in this issue.

Treasurer

Richard Myers, email: richard@carnivorousplants.org

Board Member Chris Teichreb, email: chris@carnivorousplants.org

Board Member Bob Ziemer, bob@carnivorousplants.org

Editors:

Barry A. Rice, P.O. Box 72741, Davis, CA 95617, USA, email: barry@ carnivorousplants.org

Jan Schlauer, Zwischenstr. 11, D-60594 Frankfurt, Germany, email: jan@ carnivorousplants.org

Page Layout: Steve Baker, email: steve@ carnivorousplants.org

Date of effective publication of the September 2007 issue of Carnivorous Plant Newsletter: 22 September 2007.

The ICPS is the International Cultivar Registration Authority (ICRA) for cultivated carnivorous plants according to The International Code For The Nomenclature of Cultivated Plants. Send relevant correspondence to the ICPS, Inc.

PUBLISHER: ICPS, Inc., Pinole, California. Published quarterly with one volume annually. Desktop Publishing: Steve Baker, 5612 Creek Point Drive, Hickory, NC 28601. Printer: Kandid Litho. Logo and masthead art: Paul Milauskas. Dues: \$25.00 annually. @ 2007 Carnivorous Plant Newsletter. All rights reserved. ISSN \#0190-9215. 